\title{
Role of MnO in manganese-borate binary glass systems: a study on structure and thermal properties
}

\author{
T LEWANDOWSKI*, M ŁAPIŃSKI, M WALAS, M PRZEŚNIAK-WELENC and L WICIKOWSKI \\ Department of Solid State Physics, Gdansk University of Technology, 80-233 Gdansk, Poland \\ *Author for correspondence (tlewandowski@mif.pg.gda.pl)
}

MS received 24 July 2016; accepted 23 November 2016; published online 30 August 2017

\begin{abstract}
Structural and thermal properties of $x \mathrm{MnO}-(100-x) \mathrm{B}_{2} \mathrm{O}_{3}$ (where $x=40,50$ and 60 mol\%) glass samples have been investigated with the employment of various techniques. Fourier transform infrared spectroscopy results revealed the influence of $\mathrm{MnO}$ on glass matrix. Decrease of $\mathrm{B}-\mathrm{O}$ bond-related band intensities has been observed. MnO addition was found to introduce broken $\left[\mathrm{BO}_{2} \mathrm{O}^{-}\right]_{n}$ chains. Differential scanning calorimetry (DSC) measurements presented decreasing $T_{\mathrm{g}}$ that indicates depolymerization of glass matrix in the considered compositional range. Moreover, thermal stability (TS) parameter has been evaluated using the DSC technique. It slightly decreased with MnO content. X-ray photoelectron spectroscopy results provided the evidence for $\mathrm{Mn}^{2+}$ and $\mathrm{Mn}^{3+}$ presence. Multiplet splitting, close to that of $\mathrm{MnO}$, has been observed. It has been concluded that most of the manganese ions existed in the divalent state. Photoluminescence study revealed that manganese ions are tetragonally co-ordinated in a glassy matrix.
\end{abstract}

Keywords. Mn; infrared spectroscopy; glass; thermal properties.

\section{Introduction}

Borate glasses gained significant attention owing to variety of potential applications in modern technology and engineering. For example, they find applications in non-linear optics due to high refractive index induced by high polarizability of dopants such as lead and bismuth [1]. Borate glasses doped with alkali metals are useful in UV range optics owing to their high transparency. Moreover, such glasses possess specific properties for use in sensors and glass fibres [2,3]. Introduction of magnetically active elements gives the possibility of applications in spintronics and magneto-optics [4,5]. Doping with transition metal ions (TMI) seems to be especially interesting. Transition metal oxides such as iron, cobalt and manganese exhibit good solubility in a borate matrix [6-8]. Moreover, TMIs can exist in a number of valance states, which leads to semiconducting properties of obtained materials and related applications in solar energy converters and lasers [9-12].

There are only limited number of publications addressing borate-based glasses consisting of manganese oxide [13,14]. Ardelean et al [15] studied $\mathrm{B}_{2} \mathrm{O}_{3}-\mathrm{Bi}_{2} \mathrm{O}_{3}-\mathrm{MnO}$ glasses containing up to $50 \mathrm{~mol} \%$ of $\mathrm{MnO}$. On the basis of EPR data, it was found that $\mathrm{Mn}^{2+}$ isolated ions exist in a glass matrix in octahedral symmetry [15]. Another study by WintersteinBeckmann et al [16] focused on $\mathrm{MnO}-\mathrm{SrO}-\mathrm{B}_{2} \mathrm{O}_{3}$ glass structure-property correlations. Continuous addition of $\mathrm{MnO}$ led to depolymerization of borate matrix and clustering of
$\mathrm{MnO}_{6}$ species. Binary manganese-borate glasses were studied by Kajinami et al [17] with the employment of high energy $\mathrm{X}$-ray diffraction and X-ray absorption fine structure techniques. This work suggests a gradual change of $\mathrm{BO}_{3}$ units to $\mathrm{BO}_{4}$ units as a result of $\mathrm{MnO}$ addition. Manganese ions were found to exist in tetrahedral co-ordination. Kupracz et al [18] performed a structural study on $\mathrm{MnO}-\mathrm{SiO}_{2}-\mathrm{B}_{2} \mathrm{O}_{3}$ glass systems and concluded that manganese ions exist mostly in $\mathrm{Mn}^{2+}$ state.

However, none of these works consisted of series of binary $\mathrm{MnO}-\mathrm{B}_{2} \mathrm{O}_{3}$ glasses with $\mathrm{MnO}$ content over $45 \mathrm{~mol} \%$. Possible applications in optical materials, integrated optical devices, magneto-optics and luminescent materials (luminescence of $\mathrm{Mn}^{2+}$ ions) require synthesis of glasses with good structural and thermal properties and characterization of such systems. In addition, knowledge about oxidation state of $\mathrm{Mn}$ ions is crucial. Co-existing of $\mathrm{Mn}^{2+}$ and $\mathrm{Mn}^{3+}$ in borate glass can lead to polaron conduction mechanism and semiconducting properties.

In this work, we present a study on novel binary $\mathrm{MnO}$ $\mathrm{B}_{2} \mathrm{O}_{3}$ glass systems focused on the characterization of structural and thermal properties. $\mathrm{MnO}$ influence on the borate glass is discussed and the valance state of manganese ions is examined as well. Considering the aforementioned applications, structural homogeneity, low processing temperatures and good thermal stability (TS) of materials are crucial. Successful synthesis of samples with such properties is presented. 


\section{Materials and methods}

Glass samples of $x \mathrm{MnO}-(100-x) \mathrm{B}_{2} \mathrm{O}_{3}$ (where $x=40,50$ and $60 \mathrm{~mol} \%$ ) composition have been obtained. Appropriate amounts of $\mathrm{H}_{3} \mathrm{BO}_{3}$ (99.99\% from $\mathrm{POCH}$ ) and $\mathrm{MnO}(99.99 \%$ from $\mathrm{POCH}$ ) were weighed and mixed in an agate mortar to achieve satisfactory grain size. Obtained mixtures were preheated to approximately $300^{\circ} \mathrm{C}$ for $1 \mathrm{~h}$ on a hotplate to remove gases that could eventually hinder the melting process. After removal of the gases, samples were inserted into the furnace and heated gradually to $1000^{\circ} \mathrm{C}$ in porcelain crucibles. Melts were kept at the same temperature for $30 \mathrm{~min}$. Melting process took place in atmospheric conditions. Subsequently, glasses were quenched on a pre-heated metal plate. Amorphous material was obtained in case of all samples.

$\mathrm{X}$-ray diffraction (XRD) measurements were performed on Philips X'PERT PRO X-ray diffractometer with $\mathrm{Cu}-\mathrm{K} \alpha$ radiation $(\lambda=0.154 \mathrm{~nm})$ in the range of $2 \theta=10-80^{\circ} \mathrm{C}$.

Differential scanning calorimetry (DSC) measurements were performed on NETZSCH STA 449F1. During every measurement, grounded $5 \mathrm{mg}$ samples were placed in cleaned platinum-rhodium crucibles. Heating rate of each sample equalled $15^{\circ} \mathrm{C} \mathrm{min}^{-1}$. Measurements were performed in argon atmosphere.

Fourier transform infrared spectroscopy (FTIR) results were obtained with Perkin-Elmer Frontier MIR/FIR spectrometer with TGS detector. Each sample was crushed in agate mortar until a fine grain size was achieved. Afterwards, crushed samples were mixed with potassium bromide to acquire 1:100 (sample:KBr) ratio for each sample in order to perform the measurements trough pellet method. Samples were dried in an electrical drier for few hours in order to remove the residual water content. Mixtures of glass and $\mathrm{KBr}$ were pressed on hand press to obtain transparent pellets. The spectra were taken in the range of $550-4000 \mathrm{~cm}^{-1}$ with a $2 \mathrm{~cm}^{-1}$ resolution.

X-ray photoelectron spectroscopy analysis (XPS) was carried out with X-ray photoelectron spectrometer (Omicron NanoTechnology) with 128-channel collector. Investigated samples were pre-cleaned by Ar ion beam. XPS measurement was performed at room temperature in ultra-high vacuum conditions, below $1.1 \times 10^{-8}$ mbar. The photoelectrons were excited by an $\mathrm{Mg}-\mathrm{K} \alpha \mathrm{X}$-ray source. The $\mathrm{X}$-ray anode was operated at $15 \mathrm{keV}$ and $300 \mathrm{~W}$. Omicron Argus hemispherical electron analyser with a $4 \mathrm{~mm}$ round aperture was used for analysing of emitted photoelectrons. The binding energies were corrected using the background $\mathrm{C} 1 \mathrm{~s}$ line $(285.0 \mathrm{eV})$ as a reference. XPS spectra were analysed with Casa-XPS software using a Shirley background subtraction and Gaussian-Lorentzian curve as a fitting algorithm.

Photoluminescence spectra (PL) were collected in the 515$750 \mathrm{~nm}$ range in case of emission spectra and $320-500 \mathrm{~nm}$ for excitation spectra with the employment of Perkin Elmer LS 55 spectrofluorometer. Measurements were performed using pellet samples mixed with $\mathrm{KBr}$ in weight ratio of 1:1.

\section{Results}

\subsection{XRD measurements}

$\mathrm{X}$-ray diffraction results are shown in figure 1. Obtained XRD spectra possess two wide humps in $2 \theta=20-40^{\circ} \mathrm{C}$ and 40 $60^{\circ} \mathrm{C}$ regions, indicating the absence of long range periodicity in considered samples. No sharp Bragg peak is detected in any pattern confirming lack of any crystallinity due to sufficient cooling rate during the quenching process.

\subsection{DSC results}

Differential scanning calorimetry spectra of binary manganese-borate glass samples are presented in figure 2. Glass transition temperature shifts to lower values with increasing $\mathrm{MnO}$ amount. Results presented in table 1 show decrease of $T_{\mathrm{g}}$ with increasing amount of dopant. Spectrum of $50 \mathrm{MnO}-50 \mathrm{~B}_{2} \mathrm{O}_{3}$ sample possess one crystallization peak at approximately

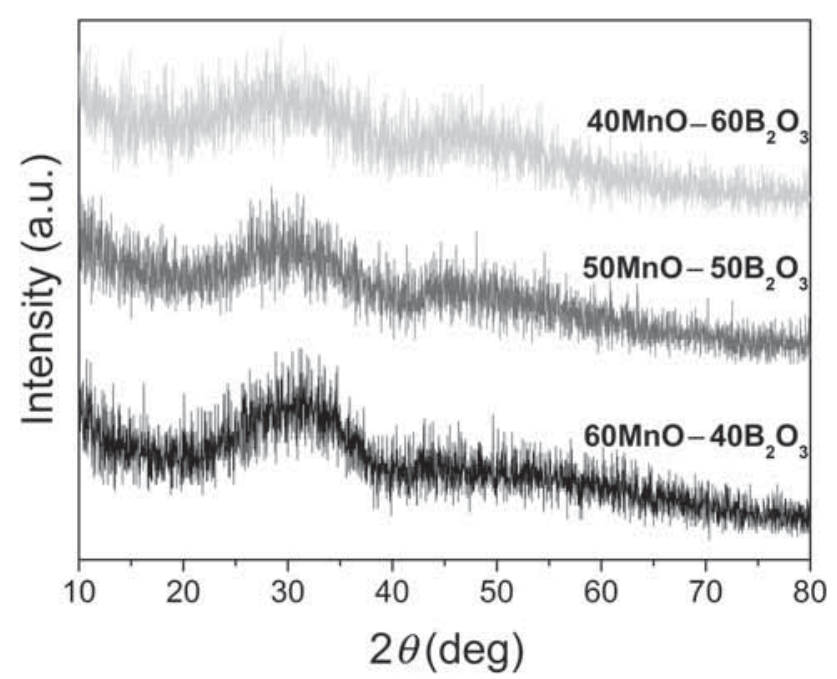

Figure 1. XRD spectra of obtained manganese-borate glass samples.

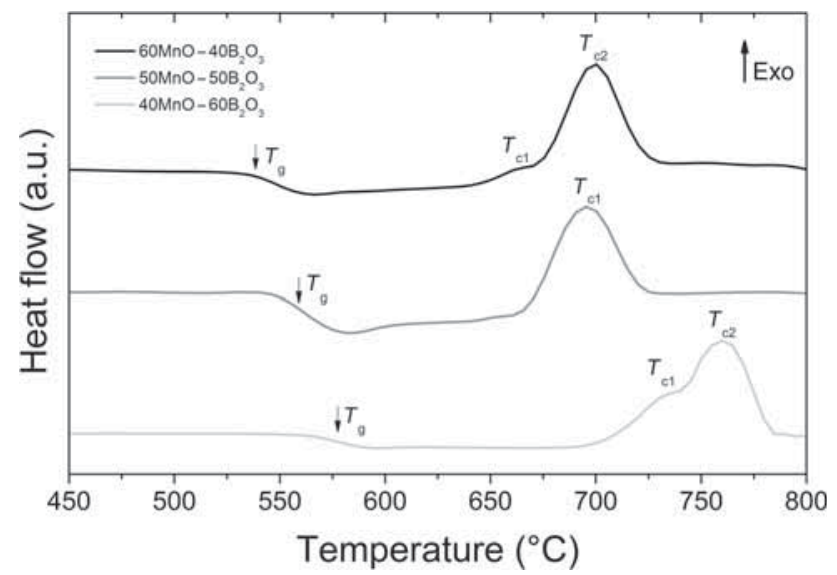

Figure 2. DSC spectra of $x \mathrm{MnO}-(100-x) \mathrm{B}_{2} \mathrm{O}_{3}$ glass samples. 
Table 1. Thermal parameters of manganese-borate glass samples.

\begin{tabular}{lccccc}
\hline Sample & $T_{\mathrm{g}}\left({ }^{\circ} \mathrm{C}\right) \pm 2{ }^{\circ} \mathrm{C}$ & $T_{\text {conset }}\left({ }^{\circ} \mathrm{C}\right) \pm 2{ }^{\circ} \mathrm{C}$ & $T_{\mathrm{c} 1}\left({ }^{\circ} \mathrm{C}\right) \pm 2{ }^{\circ} \mathrm{C}$ & $T_{\mathrm{c} 2}\left({ }^{\circ} \mathrm{C}\right) \pm 2{ }^{\circ} \mathrm{C}$ & $\mathrm{TS} \pm 2{ }^{\circ} \mathrm{C}$ \\
\hline $60 \mathrm{MnO}-40 \mathrm{~B}_{2} \mathrm{O}_{3}$ & 540 & 646 & 662 & 699 & 106 \\
$50 \mathrm{MnO}-50 \mathrm{~B}_{2} \mathrm{O}_{3}$ & 558 & 667 & 696 & - & 109 \\
$40 \mathrm{MnO}-60 \mathrm{~B}_{2} \mathrm{O}_{3}$ & 577 & 701 & 735 & 761 & 124 \\
\hline
\end{tabular}

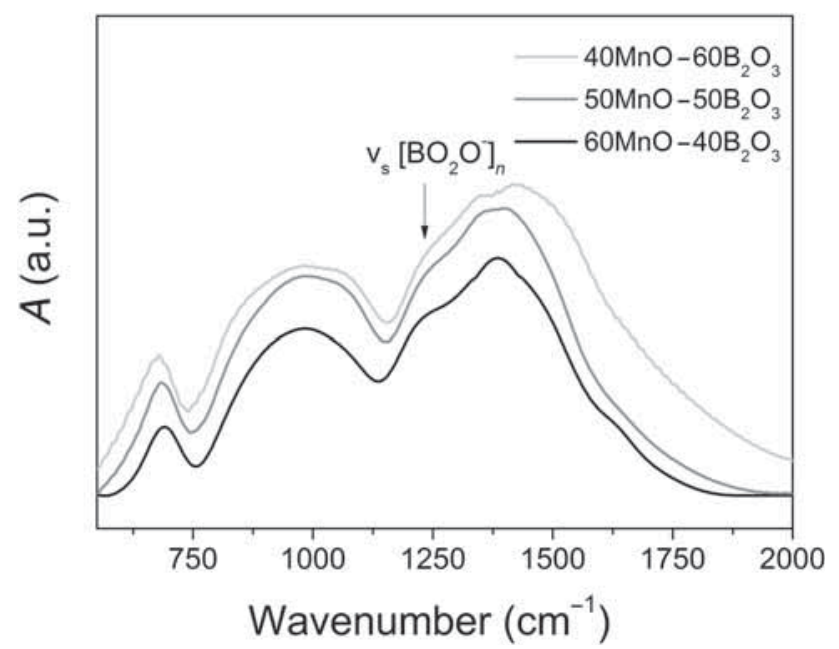

Figure 3. The obtained FTIR spectra of binary manganese-borate glass. Shoulder indicated with an arrow.

$680^{\circ} \mathrm{C}$. In case of $40 \mathrm{MnO}-60 \mathrm{~B}_{2} \mathrm{O}_{3}$ and $60 \mathrm{MnO}-40 \mathrm{~B}_{2} \mathrm{O}_{3}$ samples existence of two exothermic peaks (denoted as $T_{\mathrm{cl}}$ and $\left.T_{\mathrm{c} 2}\right)$ is confirmed. The presence of both $T_{\mathrm{c} 1}$ and $T_{\mathrm{c} 2}$ exothermic signals suggest coexistence of two crystalline phases in a considered temperature regime. In addition, with increasing $\mathrm{MnO}$ amount shift of $T_{\mathrm{c} 1}$ and $T_{\mathrm{c} 2}$ peaks to lower temperature values is observed.

Based on DSC results, TS is determined. It is expressed by TS parameter according to the equation introduced by Dietzel [19]:

$$
\mathrm{TS}=T_{\text {conset }}-T_{\mathrm{g}}
$$

where TS is thermal stability, $T_{\text {conset }}$ is the onset of the first crystallization peak and $T_{\mathrm{g}}$ is glass transition temperature. Measurement results show that influence of $\mathrm{MnO}$ on TS of prepared samples is evident. TS parameter slightly decreases with increasing $\mathrm{MnO}$.

\subsection{FTIR study}

Due to the complexity of the manganese-borate glass structure, it was necessary to perform FTIR measurements to describe alterations caused by an $\mathrm{MnO}$ addition. Figure 3 shows acquired FTIR spectra of manganese borate samples.

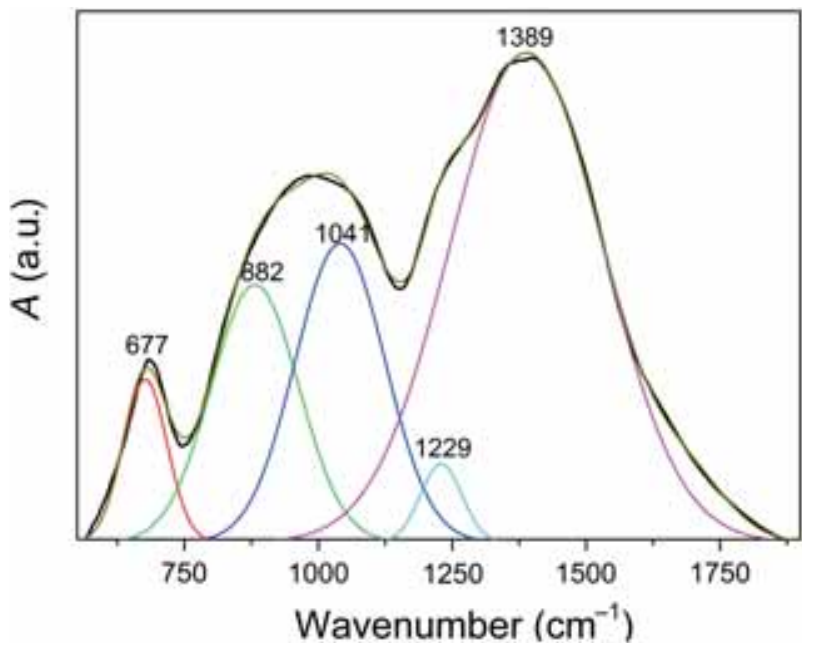

Figure 4. Fitted plot of $50 \mathrm{MnO}-50 \mathrm{~B}_{2} \mathrm{O}_{3}$ sample. Gauss functions visualized.

Each spectrum possesses three main bands $[11,12,18]$. Beginning with low wavenumber values one can notice a narrow band at approximately $680 \mathrm{~cm}^{-1}$ as a result of B-O-B bending vibrations. Wide signal in $750-1100 \mathrm{~cm}^{-1}$ range is caused by stretching vibrations of $\mathrm{B}-\mathrm{O}$ bonds in $\mathrm{BO}_{4}$ tetrahedrons from various borate groups. Finally, B-O stretching in $\left[\mathrm{BO}_{2} \mathrm{O}^{-}\right]_{n}$ chains is the origin of the last band at $1150-1500 \mathrm{~cm}^{-1}$. Shoulder indicated with an arrow symbol increases with increasing $\mathrm{MnO}$ content. This may suggest the increasing number of broken borate chains since the shoulder originates from $\mathrm{B}-\mathrm{O}$ stretching of $\left[\mathrm{BO}_{2} \mathrm{O}^{-}\right]_{n}$ species.

Fitted spectrum is presented in figure 4. Gaussian curve fitting algorithm has been used. Peak centres obtained in that manner were used in further interpretation. Detailed results are presented in table 2 .

\subsection{XPS study}

X-ray photoelectron spectroscopy spectra for $\mathrm{Mn} 2 \mathrm{p}$ and $\mathrm{Mn} 3 \mathrm{~s}$ regions are presented in figures 5 and 7, respectively. Figure 5 shows a doublet in Mn2p region. Two peaks are related to $\mathrm{Mn} 2 \mathrm{p}_{3 / 2}(642 \mathrm{eV})$ and $\mathrm{Mn} 2 \mathrm{p}_{1 / 2}(654 \mathrm{eV})$. The Mn2 $\mathrm{p}_{3 / 2}$ peaks are asymmetric due to the presence of a slight and broad shake-up peak close to $647 \mathrm{eV}$, whereas $\mathrm{Mn}_{2} \mathrm{p}_{1 / 2}$ peaks are symmetric and could be fitted by one Gaussian-Lorenzian 
Table 2. FTIR analysis results and peak positions (C).

\begin{tabular}{|c|c|c|c|}
\hline \multirow[b]{2}{*}{ Vibration } & \multicolumn{3}{|c|}{$\mathrm{C}\left(\mathrm{cm}^{-1}\right)$} \\
\hline & $40 \mathrm{MnO}-60 \mathrm{~B}_{2} \mathrm{O}_{3}$ & $50 \mathrm{MnO}-50 \mathrm{~B}_{2} \mathrm{O}_{3}$ & $60 \mathrm{MnO}-40 \mathrm{~B}_{2} \mathrm{O}_{3}$ \\
\hline $\mathrm{B}-\mathrm{O}-\mathrm{B}$ bending $[11,12,16]$ & 667 & 677 & 689 \\
\hline $\mathrm{B}-\mathrm{O}$ stretching in $\mathrm{BO}_{4}$ in diborate groups $[11,12,16]$ & 870 & 882 & 872 \\
\hline $\mathrm{B}-\mathrm{O}$ stretching in $\mathrm{BO}_{4}$ of tri-, tetra- and pentaborate groups $[11,12,16]$ & 1037 & 1041 & 1009 \\
\hline $\mathrm{B}-\mathrm{O}$ stretching in $\left[\mathrm{BO}_{2} \mathrm{O}^{-}\right]_{n}$ chains $[11,12,16]$ & 1249 & 1229 & 1219 \\
\hline $\mathrm{B}-\mathrm{O}^{-}$stretching of $\left[\mathrm{BO}_{2} \mathrm{O}^{-}\right]_{n}$ chains $[11,12,16]$ & 1429 & 1389 & 1391 \\
\hline
\end{tabular}

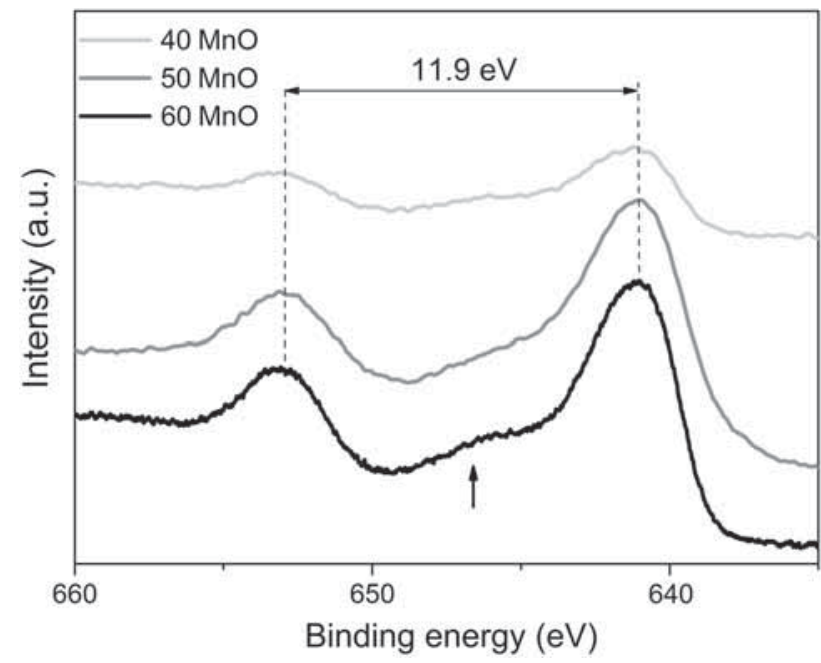

Figure 5. The obtained XPS spectra of Mn2p region. Satellite features are indicated with an arrow.

curve. The presence of the shake-up peak, the value of the splitting and the positions of $\mathrm{Mn}_{2} \mathrm{p}_{3 / 2}$ and $\mathrm{Mn} 2 \mathrm{p}_{1 / 2}$ peaks suggest that the manganese occurs mainly as $\mathrm{Mn}^{2+}$ ions [20,21]. In figure 6 , peak de-convolution for $60 \mathrm{MnO}-40 \mathrm{~B}_{2} \mathrm{O}_{3}$ glass system is presented. For this sample the highest intensities of Mn2p peaks have been obtained. The peak at $641.5 \mathrm{eV}$ is due to $\mathrm{Mn}^{2+}$ presence and the peak observed at $643 \mathrm{eV}$ is assigned to $\mathrm{Mn}^{3+}$ ions. Peak due to $\mathrm{Mn}^{2+}$ possess higher intensity than signal caused by $\mathrm{Mn}^{3+}$ ions. At $647 \mathrm{eV}$ a broad signal is observed, which is probably a satellite feature.

The obtained result is consistent with some other study [15] confirming that in highly doped borate glasses manganese can exist mostly in $\mathrm{Mn}^{2+}$ state. In addition, in figure 7 spectra for Mn3s region are presented. Mn3s peaks have two multiplet split components. Splitting between peaks is approximately $6 \mathrm{eV}$. It clearly indicates the presence of $\mathrm{Mn}^{2+}$ ions in investigated glasses [22,23]. However, the presence of some amount of $\mathrm{Mn}^{3+}$ can be detected.

\subsection{PL measurements}

Borate glasses doped with $\mathrm{Mn}^{2+}$ have potential applications as light emitters. Luminescence of these ions varies from green to red colour and is dependent on local symmetry

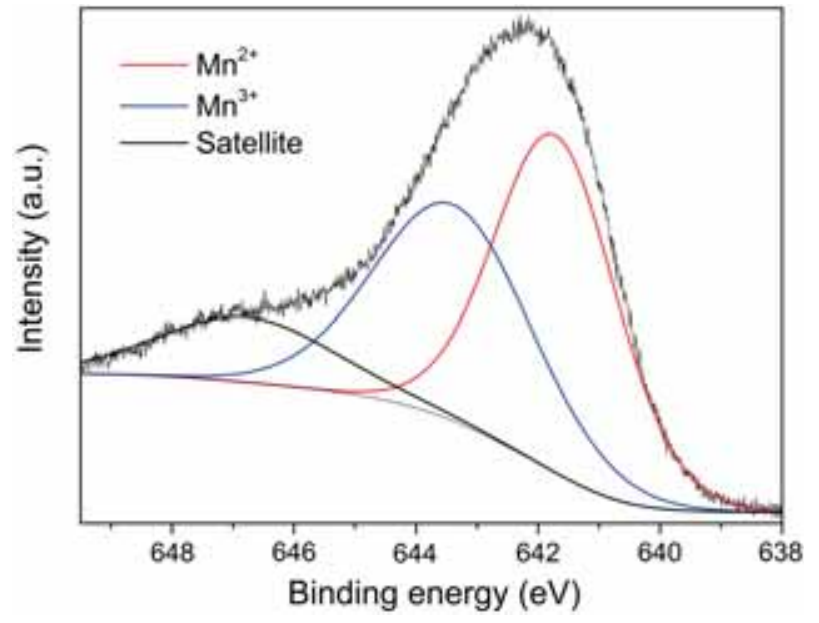

Figure 6. Peak deconvolution for $60 \mathrm{MnO}-40 \mathrm{~B}_{2} \mathrm{O}_{3}$ glass sample.

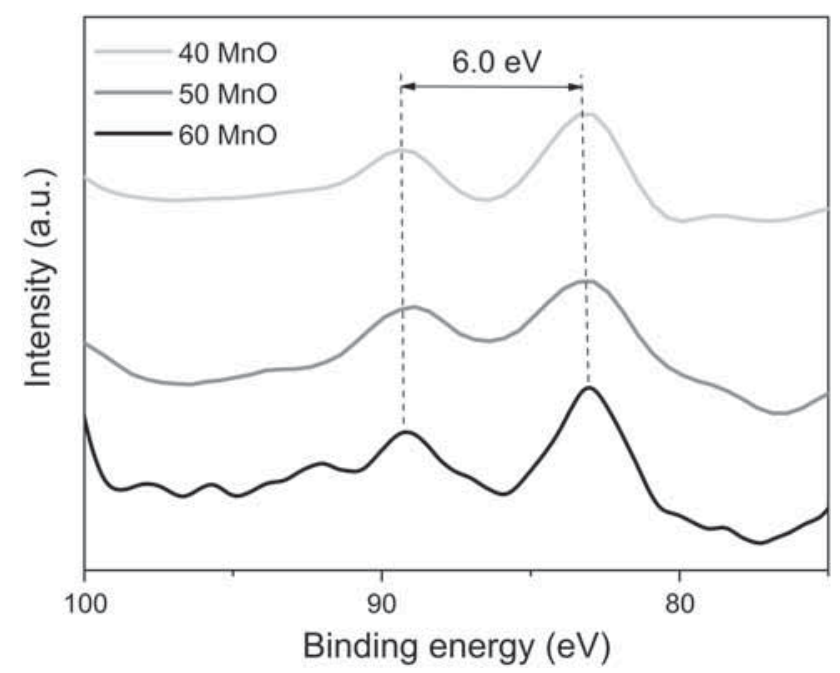

Figure 7. The obtained XPS spectra of Mn3s region.

of manganese. Thus, PL studies were performed to determine the performance of obtained samples and to give an insight about $\mathrm{Mn}^{2+}$ presence and coordination. Results are presented in figure 8 and excitation spectra of all samples are presented (left). It is worth noting that electronic states 


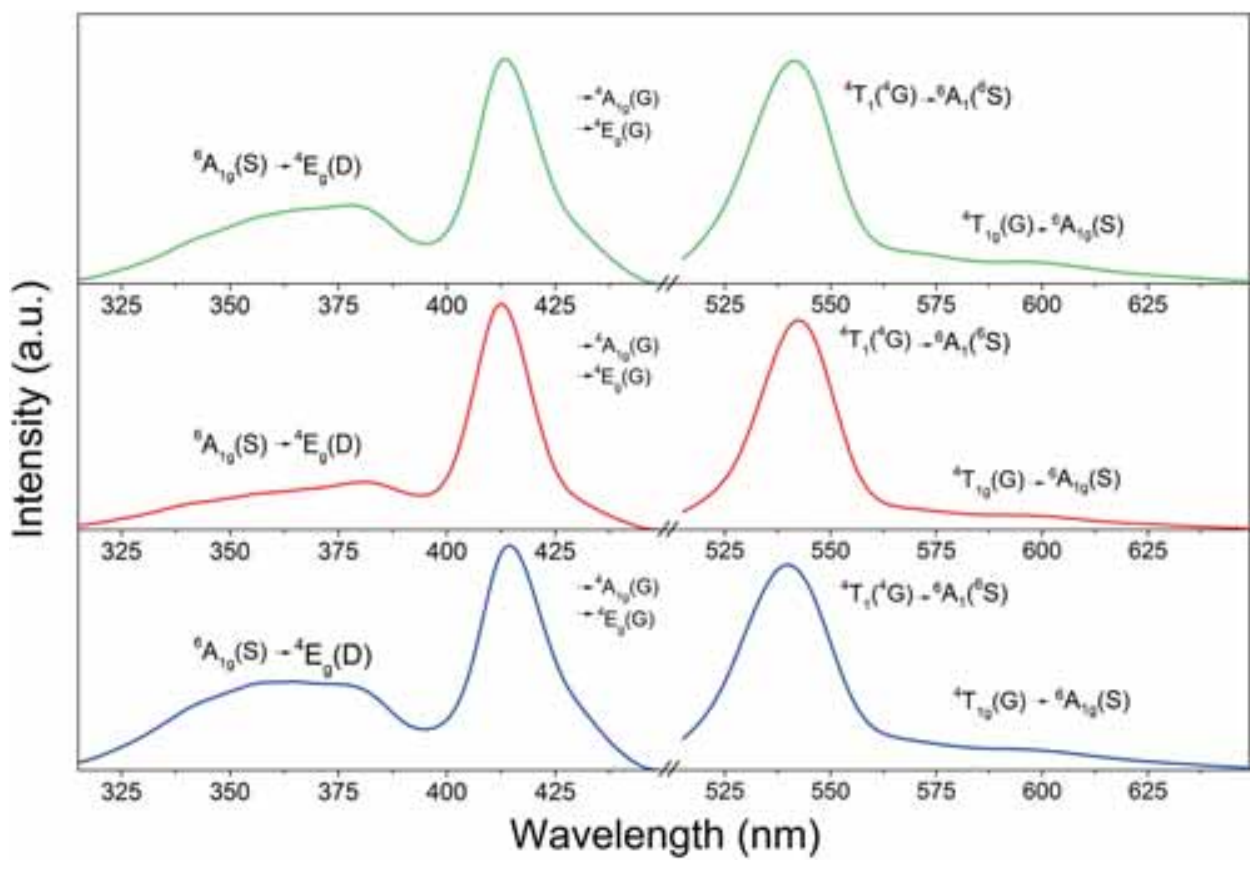

Figure 8. Results of photoluminescence measurements of obtained glass samples with different manganese content $(40,50$ and $60 \mathrm{MnO})$.

of $\mathrm{Mn}^{2+}$ ions are affected by a crystal field [24]. Relatively narrow bands are observed in the excitation spectra due to the presence of $4 \mathrm{~A} 1 \mathrm{~g}$ and $4 \mathrm{Eg}$ transitions. First, excitation band of low intensity observed at approximately $365 \mathrm{~nm}$ has its origin in ${ }^{4} \mathrm{~A}_{1 \mathrm{~g}}(\mathrm{~S}) \rightarrow{ }^{4} \mathrm{E}_{\mathrm{g}}(\mathrm{D})$ transition. Second, intensive band positioned at $413 \mathrm{~nm}$ is composed of two peaks due to ${ }^{4} \mathrm{~A}_{1 \mathrm{~g}}(\mathrm{~S}) \quad \rightarrow{ }^{4} \mathrm{~A}_{1 \mathrm{~g}}(\mathrm{G})$ and ${ }^{4} \mathrm{~A}_{1 \mathrm{~g}}(\mathrm{~S}) \quad \rightarrow{ }^{4} \mathrm{E}_{\mathrm{g}}(\mathrm{G})$ transitions. Emission spectra of binary $\mathrm{MnO}-\mathrm{B}_{2} \mathrm{O}_{3}$ glass samples are presented in figure 8 (right side). Broad, high intensity band that can be observed at approximately $540 \mathrm{~nm}$ is a result of ${ }^{4} \mathrm{~T}_{1}(\mathrm{G}) \rightarrow{ }^{6} \mathrm{~A}_{1}(\mathrm{~S})$ radiative transition, which yields green emission. Second, low intensity band at $600 \mathrm{~nm}$ can be noticed. Manganese ${ }^{4} \mathrm{~T}_{1 \mathrm{~g}}(\mathrm{G}) \rightarrow{ }^{6} \mathrm{~A}_{\mathrm{lg}}(\mathrm{S})$ transition is the source of this signal [25].

\section{Discussion}

X-ray diffraction results presented an amorphous halo. Thus, it is concluded that no long range order exists in studied samples confirming an amorphous character of obtained samples.

Acquired DSC measurement results show that both decreasing of $T_{\mathrm{g}}$ value and shift of the exothermic peaks to lower temperatures indicates degradation of borate glass structure. This process is induced by the addition of transition metal oxide. Decrease of connectivity in a glass matrix leads to observed change of TS as well. However, only slight decrease of TS parameter is observed with increasing manganese content. It might be concluded that after achieving $50 \mathrm{~mol} \%$ of $\mathrm{MnO}$, borate matrix connectivity was not significantly altered.

From FTIR results it can be deduced that the position of B$\mathrm{O}-\mathrm{B}$ bending peak slightly shifts to higher wavenumbers with increasing amount of $\mathrm{MnO}$. Wide band in $750-1100 \mathrm{~cm}^{-1}$ is composed of two peaks: one from $\mathrm{B}-\mathrm{O}$ stretching vibration in $\mathrm{BO}_{4}$ of diborate groups and the second from $\mathrm{B}-\mathrm{O}$ stretching vibration in $\mathrm{BO}_{4}$ of tri-, tetra- and pentaborate groups. These peak centre positions shift with increasing $\mathrm{Mn}$ amount. Highest wavenumber value is observed for $50 \mathrm{MnO}-50 \mathrm{~B}_{2} \mathrm{O}_{3}$ sample. On the other hand, positions of the two peaks forming the last wide band at $1200-1550 \mathrm{~cm}^{-1}$ range are shifting to lower wavenumbers with increasing $\mathrm{MnO}$ amount. With addition of $\mathrm{MnO}$, peak intensities are found to decrease as a result of gradual depolymerization of $\mathrm{MnO}-\mathrm{B}_{2} \mathrm{O}_{3}$ glass matrix. Moreover, shift of $\mathrm{B}-\mathrm{O}$ in $\mathrm{BO}_{2} \mathrm{O}^{-}$group stretching bands to lower wavenumbers is observed. The reason is weakening or elongation of $\mathrm{B}-\mathrm{O}$ bonds. It is possible that shift of $\mathrm{B}-\mathrm{O}-\mathrm{B}$ bending vibration band is caused by influence of manganese ions. Presence of atoms with larger radius leads to greater energy barrier for bending vibration of $\mathrm{B}-\mathrm{O}-\mathrm{B}$ bonds due to spatial constraints. Shoulder observed at approximately $1230 \mathrm{~cm}^{-1}\left(\mathrm{~B}-\mathrm{O}\right.$ stretching in $\left[\mathrm{BO}_{2} \mathrm{O}^{-}\right]_{n}$ signal) is increasing its intensity with addition of $\mathrm{MnO}$. Introduction of $\left[\mathrm{BO}_{2} \mathrm{O}^{-}\right]_{n}$ species suggest depolymerization of borate chains. This result is consistent with aforementioned DSC measurements that indicated decrease of matrix connectivity.

Presented XPS results confirmed the conclusion that manganese exists in two valance states, i.e., $\mathrm{Mn}^{2+}$ and $\mathrm{Mn}^{3+}$. As it can be observed Mn2p peak is composed of two bands caused 
by the presence of these two valance states. However, $\mathrm{Mn}^{2+}$ peak dominates over $\mathrm{Mn}^{3+}$ signal. Thus, it is concluded that most of the manganese ions exist in a divalent oxidation state. It is evident that the shake-up feature characteristic for $\mathrm{MnO}$ is most intensive for highest $\mathrm{MnO}$ content. Splitting among $\mathrm{Mn} 2 \mathrm{p}$ photoelectron peaks is approximately $11.9 \mathrm{eV}$, which is indicative of manganese in a divalent state. In addition, the distance between two Mn3s photoelectron peaks $(6.0 \mathrm{eV})$ corresponds to that characteristic of $\mathrm{MnO}$, confirming that $\mathrm{Mn}^{2+}$ state is dominant.

Photoluminescence measurements additionally confirmed the presence of manganese ions in a divalent state. Excitation spectra exhibit characteristic bands of manganese ions. These signals have their origin in ${ }^{4} \mathrm{~A}_{1 \mathrm{~g}}(\mathrm{~S}) \rightarrow{ }^{4} \mathrm{E}_{\mathrm{g}}(\mathrm{D}),{ }^{4} \mathrm{~A}_{1 \mathrm{~g}}(\mathrm{~S}) \rightarrow$ ${ }^{4} \mathrm{~A}_{1 \mathrm{~g}}(\mathrm{G})$ and ${ }^{4} \mathrm{~A}_{1 \mathrm{~g}}(\mathrm{~S}) \rightarrow{ }^{4} \mathrm{E}_{\mathrm{g}}(\mathrm{G})$ transitions. Emission peak due to ${ }^{4} \mathrm{~T}_{1}(\mathrm{G}) \rightarrow{ }^{6} \mathrm{~A}_{1}(\mathrm{~S})$ radiative transition is present at approximately $540 \mathrm{~nm}$. It changes its position slightly shifting to longer wavelengths. An additional low intensity band at $600 \mathrm{~nm}$ is noticeable due to $4 \mathrm{~T} 1 \mathrm{~g}(\mathrm{G}) \rightarrow 6 \mathrm{~A} 1 \mathrm{~g}(\mathrm{~S})$ transition. It has been reported that green emission of $\mathrm{Mn}^{2+}$ is indicative of its tetrahedral co-ordination and reddish-orange emission is assigned to octahedrally co-ordinated ions [25]. Considering this it can be concluded that $\mathrm{Mn}^{2+}$ ions exist mostly in tetrahedral co-ordination since their most intensive emission peak is located in the green colour region. On the other hand, low intensity red colour transition characteristic to octahedral orientation is observed. It suggests that some portion of manganese ions are octahedrally co-ordinated. No shifts of emission peaks can be noticed, which lead to the conclusion that co-ordination of manganese ions is not significantly changed with increase of manganese content. Thus, highly doped binary manganese-borate glass synthesized in this work is a good example of a green emitter in a wide compositional range.

\section{Conclusions}

Binary, amorphous manganese-borate glass samples with high manganese content (40, 50 and $60 \mathrm{~mol} \%$ of $\mathrm{MnO}$ ) were successfully synthesized. It was possible to melt stable amorphous material. FTIR, XRD, XPS and DSC techniques were employed to study obtained glass samples. As it was shown, $\mathrm{MnO}$ addition to borate glass has significant influence on structure and thermal properties of modified material. It has been concluded that gradual addition of $\mathrm{MnO}$ causes alterations of matrix structure, mainly breaking of borate chains to form $\left[\mathrm{BO}_{2} \mathrm{O}^{-}\right]_{n}$ species. Matrix depolymerization is supported by DSC results showing decrease of glass transition temperature with $\mathrm{MnO}$ addition. However, introduction of $\mathrm{MnO}$ caused only a slight decrease in TS of the obtained glasses. The XPS study revealed that manganese exists mostly in $\mathrm{Mn}^{2+}$ form. PL spectra confirmed the presence of $\mathrm{Mn}^{2+}$ ions. According to obtained results, most of the ions were tetrahedrally coordinated. The obtained low cost glass with its good structural and thermal properties is interesting material for further studies in terms of electronic and optoelectronic applications employing $\mathrm{Mn}^{2+}$ and $\mathrm{Mn}^{3+}$ ions.

\section{References}

[1] Singh N, Singh K J, Singh K and Singh H 2004 Nucl. Instrum. Methods Phys. Res. Sect. B Beam Interact. Mater. Atoms 225 305

[2] Marzouk S Y, Soliman L I, Gaafar M S, Zayed H A and El-deen A H S 2012 J. Appl. Sci. Res. 82325

[3] Zhou Y, Gai N, Wang J, Chen F and Yang G 2009 J. Lumin. 129 277

[4] Pal M 2011 J. Mod. Phys. 21062

[5] Kliava J, Edelman I, Ivanova O, Ivantsov R, Petrakovskaja E, Hennet L et al 2011 J. Magn. Magn. Mater. 323451

[6] Wen H and Tanner P A 2015 J. Alloys Compd. 625328

[7] Moustafa F A, Fayad A M, Ezz-Eldin F M and El-Kashif I 2013 J. Non-Cryst. Solids 37618

[8] Rajyasree C and Rao D K 2011 J. Non-Cryst. Solids 357836

[9] Steudel F, Loos S, Ahrens B and Schweizer S 2015 J. Lumin. 16476

[10] Ekdal E, Garcia Guinea J, Karabulut Y, Canimoglu A, Harmansah C, Jorge A et al 2015 Appl. Radiat. Isot. 10393

[11] Chen D, Xiang W, Liang X, Zhong J, Yu H, Ding M et al 2015 J. Eur. Ceram. Soc. 35859

[12] Vázquez G V, Muñoz H G, Camarillo I, Falcony C, Caldiño U and Lira A 2015 Opt. Mater. (Amst) 4697

[13] Dzhavadyan V G, Edoyan R S and Gukasyan S B 1974 Stekloobraznoe Sostoyanie p 129

[14] Sarukhanishvili A V 19795530

[15] Ardelean I, Cora S, Ciceo Lucacel R and Hulpus O 2005 Solid State Sci. 71438

[16] Winterstein-Beckmann A, Möncke D, Palles D, Kamitsos E I and Wondraczek L 2013 J. Non-Cryst. Solids 376165

[17] Kajinami A, Kotake T, Deki S and Kohara S 2003 Nucl. Instrum. Methods Phys. Res. Sect. B Beam Interact. Mater. Atoms 19934

[18] Kupracz P, Karczewski J, Prześniak-Welenc M, Szreder N A, Winiarski M J, Klimczuk T et al 2015 J. Non-Cryst. Solids 423-424 68

[19] Dietzel A 1968 Glass Tech. Berl. 2241

[20] Crist B V 2000 Handbook of monochromatic XPS spectra (Chichester: Wiley)

[21] Ehrt D 2013 Phys. Chem. Glasses. Eur. J. Glas. Sci. Technol. B 5465

[22] Biesinger M C, Payne B P, Grosvenor A P, Lau L W, Gerson A R and Smart R S 2011 Appl. Surf. Sci. 2572717

[23] van der Heide P A W 2008 J. Electron Spectroscop. Relat. Phenom. 1648

[24] Wan M H, Wong P S, Hussin R, Lintang H O and Endud S 2014 J. Alloys Compd. $\mathbf{5 9 5} 39$

[25] Gacem L, Artemenko A, Ouadjaout D, Chaminade J P, Garcia A, Pollet M et al 2009 Solid State Sci. 111854 